\title{
INTERACTIONAL JUSTICE AND COUNTERPRODUCTIVE WORK BEHAVIORS: THE MEDIATING ROLE OF NEGATIVE EMOTIONS
}

\author{
JEANNE LE ROY \\ European Business School - LAPPS, Paris \\ MARINA BASTOUNIS \\ Paris Descartes University and Rouen Business School \\ JALE Minibas-PoussaRD \\ Galatasaray University
}

\begin{abstract}
Perceptions of interactional justice have been shown to explain why employees engage in counterproductive work behaviors (CWB; Bies, 2005). However, the processes involved in this relationship have yet to be clarified. In this study, we drew on the cognitive theory of emotions and extended work published on the mediating role in this relationship (Fox \& Spector, 1999) by conducting a survey with insurance company employees $(N=187)$. Data analyses confirmed that CWB are significantly predicted by both low perceived interactional justice and negative emotions. In addition, 2 significant mediation effects were observed: (a) perceived anger mediates the relationship between low perceived interpersonal justice and active CWB, and (b) perceived fear mediates the relationship between low perceived informational justice and passive CWB. The theoretical and organizational implications of these findings are discussed.
\end{abstract}

Keywords: counterproductive work behaviors, interactional justice, organizational justice, fear, anger.

Why do employees engage in counterproductive work behaviors (CWB)? What reasons can explain employees performing below their skill levels,

Jeanne Le Roy, Department of Management, European Business School Paris - LAPPS; Marina Bastounis, Institute of Psychology, Paris Descartes University and Rouen Business School; Jale Minibas-Poussard, Business Administration Department, Galatasaray University.

Correspondence concerning this article should be addressed to: Jeanne Le Roy, Department of Management, European Business School Paris - LAPPS, 37, 39 Boulevard Murat, Paris 75016, France. Email: jeanneleroy@ebs-paris.com 
taking sick leave without really being ill, or purposely falsifying their expense accounts? In recent years, there has been an explosion of interest in CWB among organizational researchers. A large part of this work has been directed toward validating the integrity tests that human resources departments use to identify, and avoid hiring, counterproductive employees (Peterson, Griffith, Isaacson, O'Connell, \& Mangos, 2011).

Other authors have focused on determining the causes of these behaviors (Gottfredson \& Hirschi, 1990; Hodson, 2004). In one of the most influential approaches, researchers have examined CWB from a cognitive and motivational perspective (Bies \& Tripp, 1996) and suggested that CWB are the result of low perceived justice within the organization (see the meta-analyses published by Cohen-Charash \& Spector, 2001; Colquitt, Conlon, Wesson, Porter, \& Yee, 2001). This approach leads to a more complex conceptualization that draws its inspiration from the cognitive theory of emotions, according to which CWB is considered as emotion-based responses to organizational environmental conditions (Chen \& Spector, 1992; Fox \& Spector, 1999; Spector, 1975; Storms $\&$ Spector, 1987). From this perspective, the role of negative emotions would appear to function as a mediator of the relationship between low perceived organizational justice and CWB. However, very few researchers have examined the role particular emotions play in specific behaviors, such as aggression or absenteeism (Fox, Spector, \& Miles, 2001; VanYperen, Hagedoorn, Zweers, \& Postma, 2000). In this study, we integrated the cognitive approach to emotions in order to test the mediating role of the specific negative emotions of anger and fear in the relationship between perceived organizational justice and specific active and passive CWB.

\section{The Nature of CWB}

$C W B$ were defined by Spector and Fox as "volitional acts that harm or are intended to harm organizations or people in organizations" (2005, p. 151). They include overt actions (such as aggression and theft) as well as more passive actions (such as purposely failing to follow instructions or doing work incorrectly). CWB have been described in a number of ways, including organizational aggression (Baron \& Neuman, 1996; Neuman \& Baron, 1997; Spector, 1975), incivility (Andersson \& Pearson, 1999), antisocial behavior (Giacalone \& Greenberg, 1997), deviance (Hollinger, 1986; Robinson \& Bennett, 1995), and retaliation (Skarlicki \& Folger, 1997). The common underlying theme is that these behaviors harm the organization by directly affecting its functioning or property, or by impacting on employees in a way that reduces their effectiveness. A number of researchers (Buss, 1961; Conlon, Meyer, \& Nowakowski, 2005) have identified two distinct types of CWB and/or relationships between CWB and individual 
and organizational variables: active CWB (e.g., theft, aggression, sabotage) and passive CWB (e.g., withdrawal behaviors, incivility). These two types of CWB were investigated in this research.

\section{The Relationship between Perceived Interactional Injustice and CWB}

The term organizational justice refers to perceptions of fairness and evaluations concerning the appropriateness of workplace outcomes or processes (Greenberg $\&$ Colquitt, 2005). The construct is composed of three dimensions: distributive justice (Adams, 1965), which describes the perceived equity in rewards and contributions between oneself and others; procedural justice (Thibaut \& Walker, 1975), which is an evaluation of the fairness of the criteria applied during the decision-making process; and interactional justice, which is the perception of equity in the relationships between superiors and employees (Bies \& Moag, 1986).

Greenberg (1993) suggested conceptualizing interactional justice in two dimensions: informational justice and interpersonal injustice. Informational justice refers to the accuracy and quality of received information, whereas interpersonal justice describes the quality of interpersonal interactions (e.g., dignity and respect, truthfulness and propriety), particularly those between hierarchical superiors and their subordinates. Among the standard forms of justice perceptions, researchers have identified interactional justice as playing a prominent role in the emergence of CWB (for a review see Nadisic, 2008). Because the elements of interactional justice are more prevalent in the daily work environment than are the elements described in procedural and distributive justice dimensions, employees evaluate organizational exchanges on the basis of interactional justice rather than using either procedural or distributive justice criteria. This explains why, among the three types of organizational justice, low perceived interactional justice has been identified as the strongest predictor of violent behaviors in the workplace (Bies, 2005). In addition, Bies clearly demonstrated that the dimension of interactional justice facilitates the mechanism of external blame attribution, because the source of justice is easy to identify (e.g., a coworker or a hierarchical superior). Numerous studies have been conducted to test the validity of this approach, to the extent that perception of low interactional justice stands out as one of the central factors in explaining CWB (e.g., Bies \& Tripp, 1996; Jawahar, 2002; Skarlicki \& Folger, 1997).

The impact of perceived justice on CWB has generated increasing interest among researchers. Several empirical studies have been conducted in which it has been confirmed that perceptions of low interactional justice are related to verbal aggression directed toward coworkers or superiors and to a decrease in 
employee commitment (e.g., VanYperen et al., 2000). The results from a content analysis of over 100 sabotage reports written by employees (Ambrose, Seabright, \& Schminke, 2002) indicate that when interactional injustice is identified as the main cause of the sabotage, the acts of sabotage are directed not only toward other employees but also toward the organization as a whole. These results bring to light the predictive nature of low perceived interactional justice as it relates to a variety of active CWB. A laboratory experiment confirmed the causal link between low interactional justice and CWB (Burton, Mitchell, \& Lee, 2005). Participants who read a low interactional justice scenario stated that they would have engaged in both active and passive CWB more often than did the participants who read a high interactional justice scenario. Based on this literature, the following hypothesis was formulated:

Hypothesis 1: Active and passive CWB will be linked to low perceived overall interactional justice.

In other words, we expected that low perceived interactional justice scores would be significantly correlated to higher self-reported CWB, in that individuals who perceived lower interactional justice would admit to engaging in more active and passive CWB more often.

\section{The Mediating Role of Negative Emotions on the Relationship between Interactional Injustice and CWB}

Negative emotions play a central role in the interactional justice process (Krehbiel \& Cropanzano, 2000; Mikula, Scherer, \& Athenstaedt, 1998). Skarlicki and Folger suggested that "the anger and resentment associated with perceptions of unfair procedures may energize individuals to engage in retaliation" (1997, p. 435). Many scholars have pointed out the predictive role of negative emotions in producing $\mathrm{CWB}$, in that they increase the likelihood, or facilitate the production, of CWB, such as "a need to let out, or to express, one's feelings of indignation, anger, or frustration" (Robinson \& Bennett, 1997, p. 18). Therefore, negative emotion variables such as fear and anger may explain why individuals engage in CWB. Because emotions are the immediate response to situations that are perceived as unfair (Lazarus, 1991; Lovallo, 1997; Payne, 1999), and because they energize and motivate subsequent behavior and physiological change (Cartwright \& Cooper, 1997; Spector, 1988), it is possible that emotions mediate the relationship between perceived injustice and CWB. Fox and Spector (1999) found evidence of emotions mediating the relationship between organizational constraints and CWB. These authors suggested a model to explain the relationship between the perceptions of the organizational situation (i.e., justice, frustration, constraints) and engaging in CWB through the perception of emotions. In other research, it has also been suggested that negative emotions may be a mediator 
of the relationship between organizational injustice and CWB (e.g., Fox et al., 2001; VanYperen et al., 2000). In this study, our aim was to contribute to this field of research by testing the role of negative emotions as an intermediary in the relationship between perceived interactional injustice and CWB. Therefore, the following hypotheses were formulated:

Hypothesis 2: Perceived interactional justice will be negatively correlated with the measure of negative emotions.

In other words, we expected that high scores for perceived interactional justice would be linked to low self-reported negative emotions, so employees who had a more positive perception of interactional justice in their working environment than did their workmates would not score high for negative emotions:

Hypothesis 3: Negative emotions will be positively correlated with CWB.

In other words, we expected that high scores for self-reported negative emotions would be linked to high scores for self-reported CBW, so individuals who reported more negative emotions would also admit to engaging in more CBW.

Hypothesis 4: Negative emotions will mediate the relationship between perceived interactional justice and CWB.

In other words, we expected that individuals who perceived lower interactional justice in their environment than did their coworkers would engage in CWB after experiencing negative emotions.

\section{Active and Passive CWB and the Approach-Avoidance Motivational System}

Over the past two decades, the approach-avoidance motivational system has been the focus in a number of studies as a crucial element in the understanding of organizational behavior. This line of research is not new (Miller, 1944; Miller \& Dollard, 1941), but it has recently come to the fore. Varying terms are used in different fields to refer to the model: approach, incentive, and appetitive motivational system are used interchangeably. The motivational approach system is a method of describing and organizing behaviors that support action toward desired incentives. In this study, we measured such behaviors with the active CWB variable. The aversive system, on the contrary, is used to organize behaviors involved in avoiding threats. The labels aversive, threat, and avoidance or withdrawal motivational system are also used interchangeably. In this study, we measured this category of behaviors with the passive CWB variable. Oatley and Johnson-Laird (1987) emphasize that, within the approach-avoidance motivational system, each specific emotion activates a specific behavior. In this study, we focused on the impact of two specific emotions - anger and fear - on the prediction of active and passive types of CWB. More specifically, we 
addressed the relationship of these emotions to broad motivational tendencies of approach and avoidance, and we considered the possibility that these negative emotions may play the role of mediator in the relationship between interactional injustice and specific active and passive CWB.

According to the cognitive theory of emotions, each negative emotion is an early indicator of a specific behavioral response linked to either an approach or avoidance motivational strategy. For instance, anger often promotes efforts to change others' behavior and remove the violation of what "ought" to be (Fischer \& Roseman, 2007), or reopen the path toward the desired goal (Frijda, 1986). The aim in these strategies is to achieve a particular desired condition, rectify an injustice, or create discomfort for someone else (Shaver, Schwartz, Kirson, \& O'Connor, 1987). Thus, anger promotes efforts to inflict pain or harm on offenders and is linked to active CWB, such as sabotage, theft, or aggression. Whereas anger is a reaction to the actual occurrence of an aversive situation, fear is produced when there is anticipation of an aversive situation in the future, or of the given context becoming aversive in some way. Fear may protect the individual from impending danger, as it instigates defensive behavior that is associated with the fight or flight response (Cannon, 1929). Avoidance behaviors occur when an individual is trying to postpone an aversive situation or prevent it from occurring (Kanfer \& Philips, 1970). This type of behavior takes the form of passive CWB, such as absenteeism, in the context of the workplace. The link between fear and avoidance has been examined in health research (e.g., Lethem, Slade, Troup, \& Bentley, 1983; Philips, 1987; Vlaeyen \& Linton, 2000; Waddell, Newton, Henderson, Somerville, \& Main, 1993), but not in organizational contexts. In the light of this literature, we formulated the following two hypotheses.

Hypothesis 5: Anger will mediate the relationship between perceived interactional justice and active CWB.

In other words, we expected to find that individuals perceiving lower levels of interactional justice would engage in active CWB only if they were experiencing anger.

Hypothesis 6: Fear will mediate the relationship between perceived interactional justice and passive CWB.

In other words, we expected to find that individuals perceiving lower levels of interactional justice would engage in passive CWB only if they were experiencing fear.

\section{Method}

\section{Sample and Procedure}

Participants were employees in a multinational insurance company and were recruited from branch offices in Milan, Italy; Istanbul, Turkey; and Paris, France. 
Respondents were initially contacted via a letter informing them that a study was being conducted for academic research purposes in an effort to improve the understanding of some of the issues that affect people at work. Participants were assured of the confidentiality of their responses. A week later, survey packets were hand-delivered in the morning by a researcher and hand-retrieved by the researcher at the end of the same day. A sealable envelope was included in each packet to ensure confidentiality. Employees were not compensated for their participation in the study. Of 470 surveys delivered, 187 surveys were returned, for a $40 \%$ response rate; $40.8 \%$ of the respondents were male and $59.2 \%$ were female. The average age of the respondents was 39 years $(S D=9.16)$. In terms of length of service with the company, $49 \%$ of respondents had less than six years work experience and $51 \%$ of participants had six or more years work experience.

\section{Measures}

Interpersonal and informational justice. Specific justice perceptions were assessed using scales developed by Colquitt (2001). Interpersonal justice was measured using four items (Cronbach's $\alpha=.88$ ): sample item "Overall, our supervisors treat us with respect". Informational injustice was assessed using five items (Cronbach's $\alpha=.91$ ): sample item: "In my department, information is provided in detail". For all items, individuals responded on a 5-point Likert-type scale, ranging from $1=$ strongly disagree to $5=$ strongly agree .

Negative affect. We used 10 items from the Gaudreau, Blondin, and Sanchez (2003) Negative Affect Scale (NAS) to measure negative affect. Respondents used a 5-point scale to assess mood-related adjectives (ranging from $1=$ very slightly or not at all to $5=$ extremely) indicating how they generally felt at work. The NAS consists of two emotion scales (i.e., fear and anger). Fear was assessed using five items: sample item "I feel stressed" and anger using five items: sample item "I feel irritated". Scale reliabilities were Cronbach's $\alpha=.77$ for fear and .77 for anger.

CWB. CWB were measured using 12 items from the more comprehensive scales developed by Marcus, Schuler, Quell, and Hümpfner (2002). The internal consistency for the scales was acceptable: active CWB Cronbach's $\alpha=.79$, sample item: "Stolen something at work", and passive CWB Cronbach's $\alpha=.80$, sample item: "Come to work late without making excuses". Participants were asked how often they had engaged in these behaviors during the last 12 months. Items were rated on a 7 -point scale, ranging from $1=$ never to $7=$ daily.

\section{Statistical Analysis}

Data were first analyzed to obtain information about simple statistically significant relationships between variables (correlation coefficients). In order to test the mediation hypotheses, we computed a series of regression equations 
as prescribed by Baron and Kenny (1986). According to this approach, three relationships between the target variables must be demonstrated to establish a basis for testing mediation: the independent variable must predict both the dependent and the mediator variable and the mediator must predict the dependent variable. Once these conditions are established, the dependent variable is regressed onto the independent variable and the mediator in a final regression analysis.

\section{Results}

No statistically significant differences were observed among the three national groups in the sample in terms of the demographic variables.

\section{Correlational Analyses}

The results of the correlational analyses are shown in Table 1. As predicted in Hypothesis 1, the interactional justice scores, that is, interpersonal and informational, were both negatively correlated with active CWB scores $(r=-.26$ and $r=-.27$ respectively, $p \leq .01$ ). However, Hypothesis 1 was only partially confirmed because only informational justice scores were significantly and negatively correlated to passive CWB scores $(r=-.17, p \leq .05)$. Interpersonal justice scores were not related to passive CWB $(r=-.09, p=n s)$. In addition, as predicted in Hypothesis 2, the scores for the two negative emotions of anger and fear were both significantly and negatively correlated with interpersonal (anger $r=-.30$ and fear $r=-.34$, respectively, $p \leq .01$ ) and informational justice scores (anger $r=-.21$ and fear $r=-.24$, respectively, $p \leq .01$ ).

Moreover, as predicted by Hypothesis 3, the scores for anger and fear, were positively correlated with active CWB scores $(r=.45$, and $r=.34$, respectively, $p \leq .01)$. However, Hypothesis 3 was only partially confirmed because only fear scores were related to passive CWB $(r=.50, p \leq .01)$. Anger scores were not significantly correlated to passive CWB $(r=-.14, p=n s)$.

Table 1. Means, Standard Deviations, and Correlation Coefficients

\begin{tabular}{lccccccc}
\hline & $M$ & $S D$ & 1 & 2 & 3 & 4 & 5 \\
\hline 1. Anger & 1.93 & .63 & - & & & & \\
2. Fear & 2.22 & .69 & $.46^{* *}$ & - & & & \\
3. Interpersonal justice & 3.66 & .95 & $-.30^{* *}$ & $-.34^{* *}$ & - & & \\
4. Informational justice & 2.91 & .95 & $-.21^{* *}$ & $-.24^{* *}$ & $.44^{* *}$ & - & \\
5. Passive CWB & 1.36 & .48 & .14 & $.50^{* *}$ & -.09 & $-.17^{*}$ & - \\
6. Active CWB & 1.28 & .35 & $.45^{* *}$ & $.34^{* *}$ & $-.26^{* *}$ & $-.27^{* *}$ & $.45^{* *}$ \\
\hline
\end{tabular}

Note: $N=187$. $^{* *} p<.01,{ }^{*} p<.05$. 
Hypotheses 4, 5, and 6 predicted that negative emotions would mediate the relationship between perceived interactional justice and active and passive CWB. Support for mediation is obtained by demonstrating that the effect of the independent variable (interactional justice) on the dependent variable (e.g., active CWB) is significantly reduced when accounting for the effect of the hypothesized mediator (e.g., anger). The results of these analyses are shown in Figure 1. As reported above, interpersonal justice had a significant negative effect on anger (the mediator), $\beta=-.30, t(185)=-4.41, p<.001$, and active CWB (the dependent variable) $\beta=-.26, t(185)=-3.738, p<.001$. A third regression analysis established that anger was a significant predictor of active CWB, $\beta=$ $.45, t(185)=6.96, p<.001$. Finally, when the active CWB test was regressed onto both interpersonal justice and anger, the effect of interpersonal justice was reduced but remained a significant predictor of active CWB, $\beta=-.13, t(185)=$ $-2.015, p=.045$ whereas anger remained significant in the equation, $\beta=.41$, $t(185)=6.055, p<.001$. A Sobel test of the reduction in the interpersonal justice effect was significant $(Z=5.54, p<.001)$, providing support for the hypothesis that interpersonal justice interferes with active CWB by reducing anger.

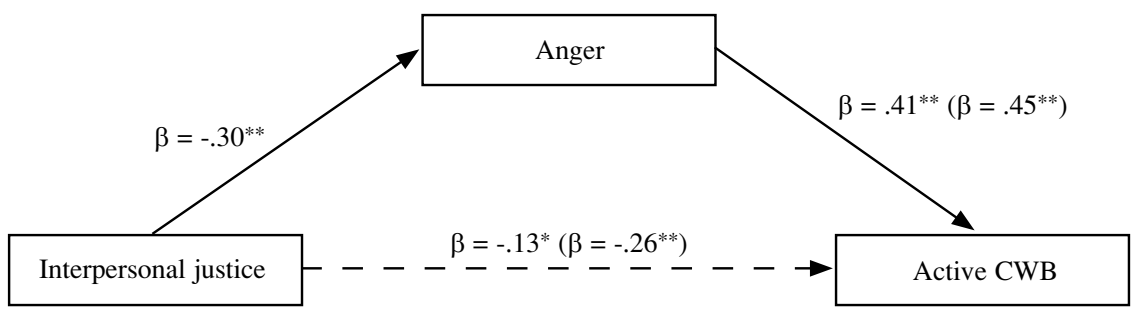

Figure 1. Tests of anger as a mediator of interpersonal justice effects on active CWB. Note: ${ }^{*} p=.045,{ }^{* *} p<.001$.

As reported above, informational justice had a significant negative effect on fear, $\beta=-.24, t(185)=-3.43, p<.001$, and passive CWB, $\beta=-.17, t(185)=$ $-2.349, p<.05$. A third regression analysis established that fear was a significant predictor of passive CWB, $\beta=.50, t(185)=8.023, p<.001$. Finally, when the passive CWB test was regressed onto both informational justice and fear, informational injustice was no longer a significant predictor of passive CWB, $\beta=-.049, t(185)=-.747, p>.45$, whereas fear remained significant in the equation, $\beta=.49, t(185)=7.587, p<.001$. A Sobel test of the reduction in the informational injustice effect was significant $(Z=4.167, p<.001)$, providing support for the prediction that informational injustice interferes with passive CWB by reducing fear (see Figure 2). These two mediation results partially support Hypotheses 4, 5 , and 6 . 


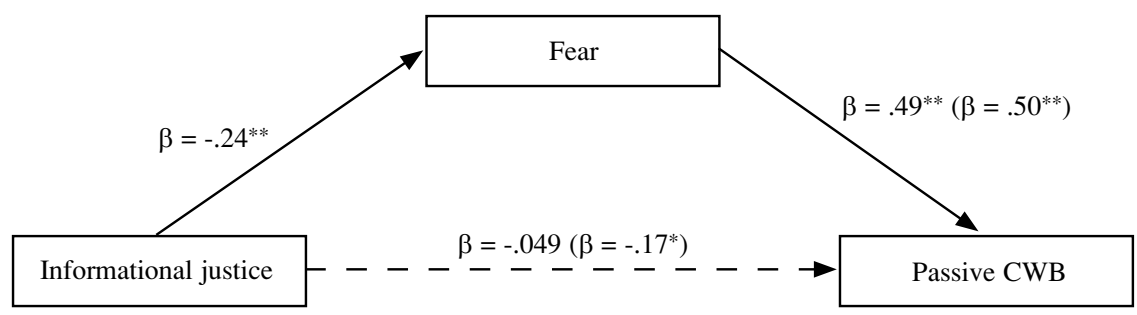

Figure 2. Tests of fear as a mediator of informational justice effects on passive CWB. Note: ${ }^{*} p=.05,{ }^{* *} p<.001$.

\section{Discussion}

Our aim in this study was to contribute to the line of work on the predictors of CWB and apply the assumptions of the cognitive theory of emotions to this field. Initially, we tested the role of low perceived interactional justice in predicting active and passive CWB. In a second step, we examined the variables that could mediate this relationship. We tested the mediating role of negative emotions (anger and fear) in the relationship between low perceived interactional justice and engaging in active and passive CWB. According to the literature, interactional injustice is an important predictor of CWB (see e.g., Fox et al., 2001; VanYperen et al., 2000) and our data tend to support the mediating role of negative emotions on that relationship. The integration of predictions based on the emotional cognitive theory allows for a better explanation of the processes leading employees to engage in CWB. We found that negative emotions, specifically anger, play a mediating role in the relationship between perceived interpersonal injustice and active CWB, meaning that, when people feel that they are being treated unfairly they feel angry, which leads them to overt motivational reactions, such as verbal aggression, sabotage, and theft. We also found that fear is a mediating variable in the relationship between low perceived informational justice and passive CWB, indicating that individuals who feel that they do not have satisfactory access to information at work feel afraid, leading them to engage in aversive behaviors (such as absenteeism and taking repeated breaks). These results are consistent with previous findings and the assumptions of the cognitive theory of emotions (e.g., Fischer \& Roseman, 2007; Frijda, 1986; Vlaeyen \& Linton 2000).

Furthermore, our data analyses confirmed the fundamental role of anger in predicting active behaviors and of fear in predicting passive withdrawal behaviors, corroborating the observations reported by Fox et al. (2001) that the emotions of hostility and fear mediate the relationship between low perceived organizational justice and CWB. Future researchers could further determine the impact of negative emotions in this context, in particular with reference to the 
stressor-emotion model developed by Spector and Fox (2005). This model takes into account organizational constraints, injustice, and stressors, and it would be instructive to test whether or not negative emotions can mediate the impact of each of these factors in explaining CWB.

Our results show that the relationship between CWB and the two dimensions of interactional justice are explained by different processes and each generates distinct CWB. We observed that the perception of unfair interpersonal treatment generates anger, which predicts more active CWB. On the other hand, the perception of not being well informed activates feelings of fear, which, in turn, can predict withdrawal reactions, or, in other words, passive CWB. These findings can be interpreted to indicate that when people feel that they lack sufficient access to quality information, they may also feel afraid of being excluded by their colleagues, their managers, and the organization (Lipiansky, 1993). Problems related to poor access to information could be seen as involving more serious problems that, in turn, are perceived as threats. The fear of being rejected by the group may lead to withdrawal behaviors, not in terms of wishing to not be rejected by others, but in rejecting others in advance.

To conclude, our results in this study suggest that each dimension of perceived interactional justice sets off a specific emotion leading to specific, distinct types of CWB. These results should be tested again in future projects. In the applied organizational context, our findings indicate the importance of managing emotions in the workplace. Employees who are better able to manage their fear could be expected to engage less in withdrawal strategies, such as passive CWB. Similarly, employees who are able to control their anger could be expected to engage in active CWB, such as theft or assault, less frequently. It has been suggested that low perceived justice is an organizational inevitability, be that through managerial decisions made on distributive justice criteria, or through perceptual biases on the part of employees (Brockner, 2006). Dealing with perceptions of injustice and the negative emotions they provoke involves key emotional intelligence capacities, such as the identification of one's own emotions and their influence, as well as the management of negative emotions in the specific environment (Goleman, 1998). Cropanzano, Weiss, Suckow, and Grandey (2000) proposed an integrative model of emotions related to injustice and illustrated how coping becomes more costly for employees who use emotionfocused coping strategies (such as hostility, accusing others, or seeking revenge). On the other hand, coping strategies focused on problem-solving support and the management of emotional reactions were found to be more cost-effective. The notion of organizational resilience is also of central significance to coping with low perceived justice. Weick, Sutcliffe, and Obstfeld (1995) proposed that in order to foster resilient reactions to organizational stressors managers should focus on sense-making, that is, the process by which people give meaning to experience. 
Bies and Tripp (1998) showed that, when faced with a situation of organizational unfairness, employees may adopt CWB (organizational retaliation) or constructive behavior, such as making a deliberate decision to forego anger, resentment, and the desire to punish the person responsible for the prejudice (Murphy, 1988). The term reinvestment is used to describe the behaviors that occur when employees who feel that they have been treated unfairly attempt to restore or reconstruct the damaged relationships (McCullough, Worthington, \& Rachal, 1997). The development of emotional intelligence, efficient environmental stress reduction, problem-focused coping, and increased resilience through sense-making, are all instrumental in creating a situation in which employees who perceive that there is little justice in their workplace resort to behaviors of reinvestment instead of CWB.

\section{References}

Adams, J. S. (1965). Inequity in social exchange. In L. Berkowitz (Ed.), Advances in experimental social psychology (Vol. 2, pp. 267-299). New York: Academic Press.

Ambrose, M., Seabright, M. A., \& Schminke, M. (2002). Sabotage in the workplace: The role of organizational injustice. Organizational Behavior and Human Decision Processes, 89, 947-965. http://doi.org/cbqzjw

Andersson, L. M., \& Pearson, C. M. (1999). Tit for tat? The spiraling effect of incivility in the workplace. Academy of Management Review, 24, 452-471. http://doi.org/czn8bc

Baron, R. M., \& Kenny, D. A. (1986). The moderator-mediator variable distinction in social psychological research: Conceptual, strategic, and statistical considerations. Journal of Personality and Social Psychology, 51, 1173-1182. http://doi.org/d7bst5

Baron, R. A., \& Neuman, J. H. (1996). Workplace violence and workplace aggression: Evidence on their relative frequency and potential causes. Aggressive Behavior, 22, 161-173. http:// doi.org/c8fsq3

Bies, R. J. (2005). Are procedural justice and interactional justice conceptually distinct? In J. Greenberg \& J. A. Colquitt (Eds.), Handbook of organizational justice (pp. 85-112). Mahwah, NJ: Erlbaum.

Bies, R. J., \& Moag, J. S. (1986). Interactional justice: Communication criteria for fairness. In B. Sheppard (Ed.), Research on negotiation in organizations (Vol. 1, pp. 43-55). Greenwich, CT: JAI.

Bies, R. J., \& Tripp, T. M. (1996). Beyond distrust: "Getting even" and the need for revenge. In R. M. Kramer \& T. R. Tyler (Eds.), Trust in organizations (pp. 246-260). Thousand Oaks, CA: Sage.

Bies, R. J., \& Tripp, T. M. (1998). The many faces of revenge: The good, the bad, and the ugly. In R. W. Griffin, A. O’Leary-Kelly, \& J. Collins (Eds.), Monographs in organizational behavior and industrial relations: Vol. 23. Dysfunctional behavior in organizations: Part B. Non-violent dysfunctional behavior (pp. 49-67). Greenwich, CT: JAI.

Brockner, J. (2006). Why it's so hard to be fair. Harvard Business Review, 84, 122-129. http://hbr. org

Burton, J. P., Mitchell, T. R., \& Lee, T. W. (2005). The role of self-esteem and social influences in aggressive reactions to interactional injustice. Journal of Business and Psychology, 20, 131-170. http://doi.org/c4g25t

Buss, A. H. (1961). The psychology of aggression. New York: Wiley. 
Cannon, W. B. (1929). Bodily changes in pain, hunger, fear, and rage: An account of recent researches into the function of emotional excitement. New York: Appleton Century Crofts.

Cartwright, S., \& Cooper, C. L. (1997). Managing workplace stress. Thousand Oaks, CA: Sage.

Chen, P. Y., \& Spector, P. E. (1992). Relationships of work stressors with aggression, withdrawal, theft, and substance use: An exploratory study. Journal of Occupational and Organizational Psychology, 65, 177-184. http://doi.org/bs9w28

Cohen-Charash, Y., \& Spector, P. E. (2001). The role of justice in organizations: A meta-analysis. Organizational Behavior and Human Decision Processes, 86, 278-321. http://doi.org/bmzwxt

Colquitt, J. A. (2001). On the dimensionality of organizational justice: A construct validation of a measure. Journal of Applied Psychology, 86, 386-400. http://doi.org/bg5rq9

Colquitt, J. A., Conlon, D. E., Wesson, M. J., Porter, C. O., \& Yee, N. K. (2001). Justice at the millennium: A meta-analytic review of 25 years of organizational justice research. Journal of Applied Psychology, 86, 425-445. http://doi.org/cpmf2x

Conlon, D. E., Meyer, C. J., \& Nowakowski, J. M. (2005). How does organizational justice affect performance, withdrawal, and counterproductive behavior? In J. Greenberg \& J. A. Colquitt (Eds.), Handbook of organizational justice (pp. 301-328). Mahwah, NJ: Erlbaum.

Cropanzano, R., Weiss, H. M., Suckow, K. J., \& Grandey, A. A. (2000). Doing justice to workplace emotion. In N. M. Ashkanasy, C. E. Härtel, \& W. J. Zerbe (Eds.), Emotions in the workplace: Research, theory, and practice (pp. 49-62). London, England: Quorum Books.

Fischer, A. H., \& Roseman, I. J. (2007). Beat them or ban them: The characteristics and social functions of anger and contempt. Journal of Personality and Social Psychology, 93, 103-115. http://doi.org/fvr7h2

Fox, S., \& Spector, P. E. (1999). A model of work frustration-aggression. Journal of Organizational Behavior, 20, 915-931. http://doi.org/fqmpcg

Fox, S., Spector, P. E., \& Miles, D. (2001). Counterproductive work behavior (CWB) in response to job stressors and organizational justice: Some mediator and moderator tests for autonomy and emotions. Journal of Vocational Behavior, 59, 291-309. http://doi.org/d998q4

Frijda, N. H. (1986). The emotions. Cambridge, England: Cambridge University Press.

Gaudreau, P., Blondin, J.-P., \& Sanchez, X. (2003). Positive and negative affective states in a performance-related setting: Testing the factorial validity of the PANAS across two samples of French-Canadian participants. European Journal of Psychological Assessment, 22, 240-249. http://doi.org/dm8jcq

Giacalone, R. A., \& Greenberg, J. (1997). Antisocial behavior in organizations. Newbury Park, CA: Sage.

Goleman, D. (1998). Working with emotional intelligence. New York: Bantam.

Gottfredson, M. R., \& Hirschi, T. (1990). A general theory of crime. Stanford, CA: Stanford University Press.

Greenberg, J. (1993). Stealing in the name of justice: Informational and interpersonal moderators of theft reactions to underpayment inequity. Organizational Behavior and Human Decision Processes, 54, 81-103. http://doi.org/b5jp2m

Greenberg, J., \& Colquitt, J. A. (2005). The handbook of organizational justice. Mahwah, NJ: Erlbaum.

Hodson, R. (2004). A meta-analysis of workplace ethnographies: Race, gender, and employee attitudes and behaviors. Journal of Contemporary Ethnography, 33, 4-38. http://doi.org/bd27k2

Hollinger, R. C. (1986). Acts against the workplace: Social bonding and employee deviance. Deviant Behavior, 7, 53-75. http://doi.org/cx65kb

Jawahar, I. M. (2002). A model of organizational justice and workplace aggression. Journal of Management, 28, 811-834. http://doi.org/cmh3mc

Kanfer, F. H., \& Philips, J. S. (1970). Learning foundations of behavior therapy. New York: Wiley. 
Krehbiel, P. J., \& Cropanzano, R. (2000). Procedural justice, outcome favorability, and emotion. Social Justice Research, 13, 339-360. http://doi.org/cksr77

Lazarus, R. S. (1991). Emotion and adaptation. New York: Oxford University Press.

Lethem, J., Slade, P. D., Troup, J. D. G., \& Bentley, G. (1983). Outline of a fear-avoidance model of exaggerated pain perception. Behaviour Research and Therapy, 21, 401-408. http://doi.org/ cg3b6d

Lipiansky, E. M. (1993). L'identité dans la communication [Identity in communication]. Psychologie de la Communication, 97, 31-37.

Lovallo, W. R. (1997). Stress and health: Biological and psychological interactions. Thousand Oaks, CA: Sage.

McCullough, M. E., Worthington, E. L., Jr., \& Rachal, K. C. (1997). Interpersonal forgiving in close relationships. Journal of Personality and Social Psychology, 73, 321-336. http://doi.org/dch699

Marcus, B., Schuler, H., Quell, P., \& Hümpfner, G. (2002). Measuring counterproductivity: Development and initial validation of a German self-report questionnaire. International Journal of Selection and Assessment, 10, 18-35. http://doi.org/b9xxmn

Miller, N. E. (1944). Experimental studies of conflict. In J. Hunt (Ed.), Personality and the behavior disorders (Vol. 1, pp. 431-465). New York: Ronald.

Miller, N. E., \& Dollard, J. (1941). Social learning and imitation. New Haven, CT: Yale University Press.

Mikula, G., Scherer, K. R., \& Athenstaedt, U. (1998). The role of injustice in the elicitation of differential emotional reactions. Personality and Social Psychology Bulletin, 24, 769-783. http:// doi.org/dz2f9g

Murphy, J. G. (1988). Forgiveness and resentment. In J. G. Murphy \& J. Hampton (Eds.), Forgiveness and mercy (pp. 14-33). Cambridge, England: Cambridge University Press.

Nadisic, T. (2008). Pourquoi les managers ajoutent-ils de l'injustice à l'injustice? Les antécédents de l'effet Churchill [Why do managers add injustice to injustice? The antecedents of the Churchill effect]. Revue Française de Gestion, 183, 221-250. http://rfg.revuesonline.com/acceuil.jsp

Neuman, J. H., \& Baron, R. A. (1997). Aggression in the workplace: A social-psychological perspective. In R. A. Giacalone \& J. Greenberg (Eds.), Antisocial behavior in organizations (pp. 37-67). Thousand Oaks, CA: Sage.

Oatley, K., \& Johnson-Laird, P. N. (1987). Towards a cognitive theory of emotions. Cognition and Emotion, 1, 29-50. http://doi.org/d3mw2t

Payne, R. (1999). Stress at work: A conceptual framework. In J. Firth-Cozens \& R. Payne (Eds.), Stress in health professionals: Psychological and organisational causes and interventions (pp. 3-16). Chichester, England: Wiley.

Peterson, M. H., Griffith, R. L., Isaacson, J. A., O’Connell, M. S., \& Mangos, P. M. (2011). Applicant faking, social desirability, and the prediction of counterproductive work behaviors. Human Performance, 24, 270-290. http://doi.org/bdx43b

Philips, H. C. (1987). Avoidance behaviour and its role in sustaining chronic pain. Behaviour Research and Therapy, 25, 273-279. http://doi.org/bhstgf

Robinson, S. L., \& Bennett, R. J. (1995). A typology of deviant workplace behaviors: A multidimensional scaling study. Academy of Management Journal, 38, 555-572. http://doi.org/bcp4wk

Shaver, P., Schwartz, J., Kirson, D., \& O’Connor, C. (1987). Emotion knowledge: Further exploration of a prototype approach. Journal of Personality and Social Psychology, 52, 1061-1086. http:// doi.org/d66zfb

Skarlicki, D. P., \& Folger, R. (1997). Retaliation in the workplace: The roles of distributive, procedural, and interactional justice. Journal of Applied Psychology, 82, 434-443. http://doi. org/cq9gqv 
Spector, P. E. (1975). Relationship of organizational frustration with reported behavioral reactions of employees. Journal of Applied Psychology, 60, 635-637. http://doi.org/fn5v8r

Spector, P. E. (1988). Development of the Work Locus of Control Scale. Journal of Occupational Psychology, 61, 335-340. http://doi.org/dx487c

Spector, P. E., \& Fox, S. (2005). A model of counterproductive work behavior. In S. Fox \& P. E. Spector (Eds.), Counterproductive workplace behavior: Investigations of actors and targets (pp. 151-174). Washington, DC: American Psychological Association.

Storms, P. L., \& Spector, P. E. (1987). Relationships of organizational frustration with reported behavioural reactions: The moderating effect of locus of control. Journal of Occupational Psychology, 60, 227-234. http://doi.org/d8wf3m

Thibaut, J. W., \& Walker, L. (1975). Procedural justice: A psychological analysis. Hillsdale, NJ: Erlbaum.

VanYperen, N. W., Hagedoorn, M., Zweers, M., \& Postma, S. (2000). Injustice and employees' destructive responses: The mediating role of state negative affect. Social Justice Research, 13, 291-312. http://doi.org/bf6bdt

Vlaeyen, J. W. S., \& Linton, S. J. (2000). Fear-avoidance and its consequences in chronic musculoskeletal pain: A state of the art. Pain, 85, 317-332. http://doi.org/c6p5nz

Weick, K. E., Sutcliffe, K. M., \& Obstfeld, D. (1995). Organizing and the process of sense-making. Organization Science, 16, 409-421. http://doi.org/c3ktpm

Waddell, G., Newton, M., Henderson, I., Somerville, D., \& Main, C. J. (1993). A Fear-Avoidance Beliefs Questionnaire (FABQ) in the role of fear-avoidance beliefs in chronic low back pain and disability. Pain, 52, 157-168. http://doi.org/d4hqqz 
